\title{
AVALIAÇÃO DA VEGETAÇÃO ARBÓREA NAS PRINCIPAIS RUAS DA CIDADE DO HUAMBO-ANGOLA
}

\author{
ARBOREAL VEGETATION ASSESSMENT ON MAIN STREETS OF \\ HUAMBO CITY - ANGOLA
}

\author{
Isaú Alfredo Bernardo Quissindo; Emir Falcón Oconor²; Damarys Pérez Luna³
}

\section{RESUMO}

Com o propósito de avaliar a vegetação arbórea nas principais ruas da cidade do Huambo desenvolveuse um inventário das árvores destas zonas, mas previamente realizou-se a identificação das espécies arbóreas. Para avaliar a vegetação, fez-se um levantamento de dados nas principais ruas da cidade (Avenida Norton de Matos, Rua Presidente Craveiro Lopes, Rua Dr. Carlos Ferreira, Avenida da República e Rua Ferreira Viana) mediante um formulário, com as seguintes variáveis: comprimento das ruas, nome da espécie, diâmetro do tronco (DAP), altura livre dos ramos e altura total. Como resultado constatou-se que a vegetação arbórea nas principais ruas está composta por 11 famílias, 16 gêneros, 16 espécies e 552 árvores que representa $47,60 \%$, valor baixo nos $5800 \mathrm{~m}$ de extensão total entre as seis ruas. De acordo os parâmetros dendrométricos avaliados a maioria das árvores são adultas e em alguns casos necessitam de reposições devido às péssimas condições morfológicas que apresentam. Foi ainda avaliada a composição vegetativa nas ruas em estudo, onde observou-se semelhança da mesma composição e distinguiu-se dois grupos de ruas (três por cada) que tiveram estrutura vegetal homogenea.

Palavras-chave: Caracterização; Vegetação urbana; Arborização viária.

\section{ABSTRACT}

In order to evaluate the arboreal vegetation in Huambo city's main streets, an inventory of trees in these areas was developed, but previously the identification of tree species was held. To assess the vegetation, data were collected on the main streets of the city (Avenue Norton de Matos, Presidente Craveiro Lopes Street, Dr. Carlos Ferreira Street, Avenue of the Republic and Ferreira Viana Street) by a form with the following variables: length of streets, species name, trunk diameter $(\mathrm{DBH})$, headroom of branches and total height. As a result it was found that the arboreal vegetation on the main streets is composed of 11 families, 16 genera, 16 species and 552 trees representing $47.60 \%$, low value in the $5800 \mathrm{~m}$ total length of the six streets. According to the dendrometric parameters evaluated, most of the trees are mature and in some cases require replacements due to poor morphological conditions present. It was also evaluated the vegetative composition in the studied streets where was observed similarity of the same composition and distinguished two streets groups (three each) which had homogeneous plant structure.

Keywords: Characterization; Urban greenery; Street tree.

Recebido em 30.01.2016 e aceito em 26.04.2016

1 Engenheiro Florestal pela Faculdade de Ciências Agrárias/Chianga da Universidade José Eduardo dos Santos/Huambo-Angola, Mestrando em Geomática, Teledetecção e Modelos Espaciais aplicada à Gestão Florestal pela Universidade de Córdoba/Espanha. Email para correspondência: josuealf.2011@hotmail.com.

2 Engenheiro Florestal, Professor Auxiliar na Universidade José Eduardo dos Santos/Huambo-Angola em vínculo com a Universidade de Guantánamo, Cuba. Email para correspondência: emirfalconoconor@gmail.com.

3 Engenheira Agrónomo, MSc., Professora Assistente na Universidade José Eduardo dos Santos/Huambo-Angola em vínculo com a Universidade de Ciego de Avila, Cuba. Email para correspondência: damarysluna42@gmail.com. 


\section{INTRODUÇÃO}

As árvores proporcionam benefícios fundamentais para o meio urbano a medida que contribuem para regulação do microclima, melhoria da qualidade do ar, fornecimento de sombra e bem-estar físico e psicológico à população. Desta forma, a arborização viária deve ser entendida como elemento essencial para proteção do meio urbano, pois oferece benefícios à qualidade de vida da população nas cidades, seja no âmbito estético, psicológico e socioeconômico (SANTOS; LISBOA; CARVALHO, 2012).

Atualmente muitas zonas urbanas do mundo apresentam muitos e, cada vez mais, graves problemas ambientais que estão pondo em risco a sustentabilidade de seu desenvolvimento. É por isso que as árvores plantadas nas cidades, principalmente do terceiro mundo, dão um grande contributo às condições de vida atual, tendo um potencial cada vez ainda maior (JIMÉNEZ, 2009).

Nos dias de hoje, é notória a escassez de áreas verdes públicas adequadas e espaços verdes mal cuidados nas cidades angolanas e não só. Entretanto, é necessário valorizar estes espaços, já que a árvore no meio urbano representa um património paisagístico pelo seu valor estético e ambiental; património social, pela melhoria e contribuição ao espaço vital e seu papel climático; património histórico como elemento de acompanhamento da arquitetura e feitos ligados a ele e património botânico (VOLPE-FILIK; SILVA; LIMA, 2007; HAMADA; OHTA, 2010). Portanto, o espaço verde é que eleva o padrão de uma cidade e oferece qualidade de vida a seus habitantes, de um ponto de vista ambiental e ecológico.

Em Angola, na África, o manejo das áreas verdes de uso público está principalmente vinculado às administrações municipais, mas estas nem sempre contam com os meios e o pessoal para atenderem as necessidades administrativas sobre estas áreas, e isto deve-se à diversos problemas (como falta de planejamento, mão-de-obra não qualificada, financiamento insuficiente, falta de capacitação, extensão e comunicação, entre outras) que, claramente, evidenciam-se quando avaliadas em relação a outros países (ANGOP, 2013).

O presente trabalho focou seus estudos nas principais ruas da cidade do Huambo, já que estas dinamizam as outras que caracterizam os distintos setores da cidade, a qual possui um notável déficit de áreas verdes em relação a sua população estando sujeito, assim, aos problemas que afetam outros países. Sua importância fundamenta-se na obtenção de uma base de dados atualizada com a caracterização da vegetação arbórea nas ruas e sua condição atual. Por outro lado, permite conhecer o valor econômico e propõe medidas de melhoramento que contribuam a futuras propostas de manejo relativas ao desenho, manutenção e seleção da vegetação arbórea pública. 
Devido a falta de manutenção da maior parte da vegetação na cidade do Huambo, este estudo teve como principal objetivo avaliar a vegetação arbórea nas principais ruas desta cidade.

\section{MATERIAL E MÉTODOS}

\section{Área de Estudo}

O estudo foi realizado de agosto à outubro de 2014 nas principais ruas da cidade do Huambo/Angola que segundo Wanda (2007) no Roteiro do Huambo são: Rua 5 de Outubro, Avenida Norton de Matos, Rua Presidente Craveiro Lopes, Rua Doutor Carlos Ferreira, Avenida da República e Rua Ferreira Viana. Estas, que são as principais vias de acesso da cidade do Huambo (Figura 1), estão localizadas entre as seguintes coordenadas geográficas: $12^{\circ} 46^{\prime} 00^{\prime \prime} \mathrm{S}$ e $15^{\circ} 44^{\prime} 00^{\prime \prime} \mathrm{E}$. A cidade está a mais de 1300 metros acima do nível do mar, no entanto uma grande parte atinge altitudes superiores a 1700 metros. É a cidade capital da província que leva o mesmo nome, fundada em 1912 e, mais tarde, em 1929, chamada Nova Lisboa (MENDELSOHN; WEBER, 2013).
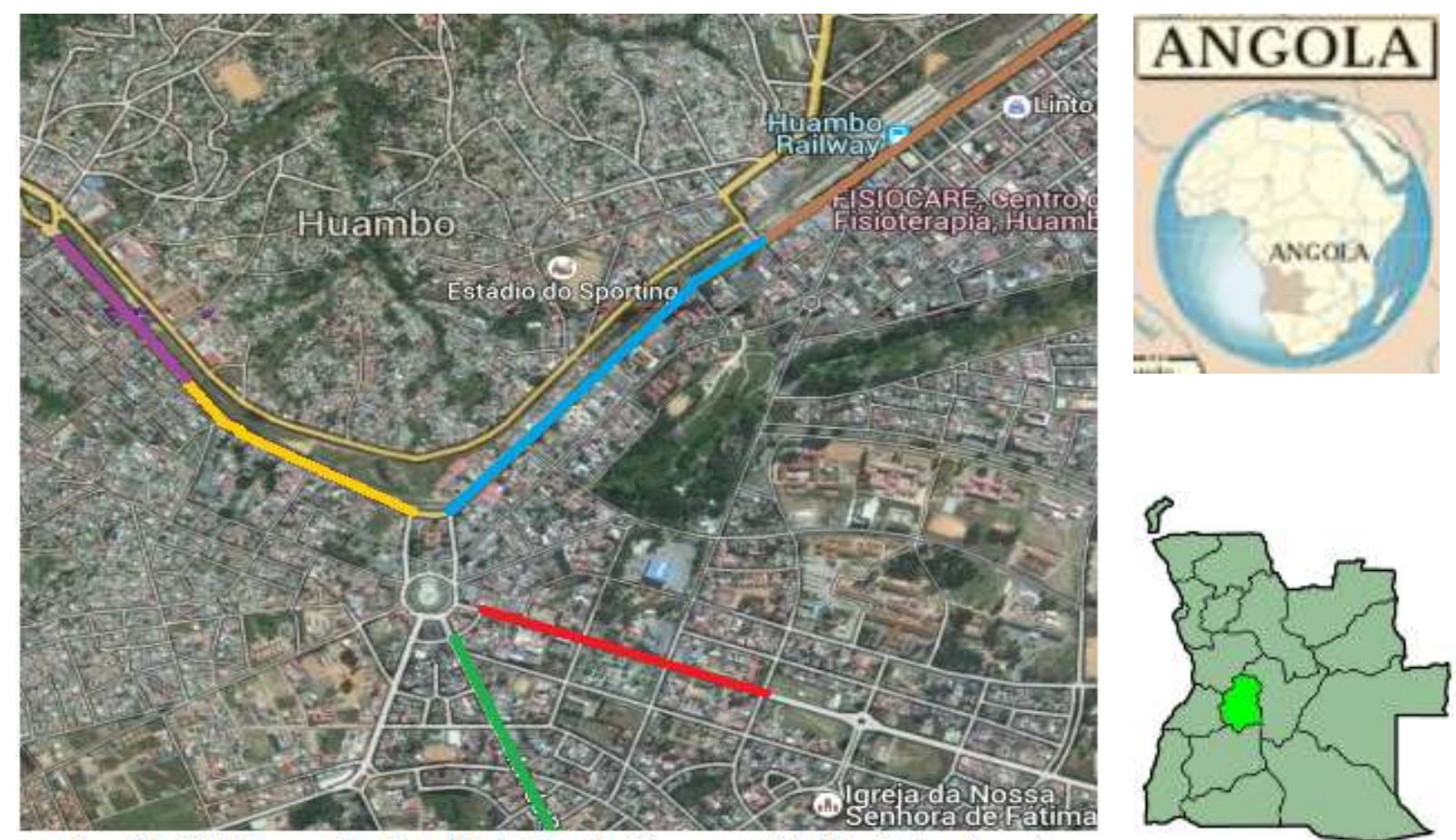

Rua 5 de Outubro Rua Presidente Craveiro Lopes Rua Dr. Carlos Ferreira Rua Ferreira Viana _Avenida da República _Avenida Norton de Matos

Fonte: Google Earth, 2015

Figura 1. Mapa da Cidade do Huambo, Angola

Figure 1. Map of Huambo City, Angola 
É a segunda cidade mais alta e mais fria de Angola após o Lubango que fica ao sul dela e que é um pouco mais alta que ela estando a $2^{\circ}$ graus ao sul do Huambo. Está localizada sobre um Planalto acima de $1774 \mathrm{~m}$ de altitude e possui um clima Tropical de Altitude (Cwb) ou Clima Oceânico (Cwb). Caracterizado por Verões húmidos e mornos, com noites amenas e dias relativamente quentes e Invernos secos com dias amenos e noites relativamente frias. A província em geral e a cidade particularmente tem um clima alternante úmido e seco por influência da altitude, a temperatura média anual é de $19^{\circ} \mathrm{C}$, tendo uma mínima de $15^{\circ} \mathrm{C}$ e máxima de 20ํㅡ, marcada por duas estações (DELGADO; JIMÉNEZ; KIALA, 2007).

\section{Tamanho da Amostra}

Wanda (2007) no Roteiro da cidade Huambo considera que nesta cidade existem seis (6) ruas principais. Considerando este critério, realizou-se uma amostragem piloto ou prévia nas seis ruas principais utilizando como variável de interesse o número de espécies acumuladas. Para determinar se o tamanho de amostragem foi suficiente analisou-se a curva de riqueza de espécies, onde se relacionam o número acumulado de novas espécies por unidade de amostragem, neste caso ruas; esta é a chamada curva do colector nos trabalhos de taxonomia por Schilling e Batista (2008) ou curva espécie/área por Schilling, Ferreira e Do Couto (2012). Esta relação é utilizada para determinar a área mínima de amostragem. Isto é, obter uma área mínima que assegure que dentro dela estão representadas quase a totalidade das espécies arbóreas.

\section{Identificação e Quantificação da Vegetação Arbórea nas Principais Ruas}

Mediante o auxílio de máquina fotográfica e um mesmo modelo de planilhas para as seis ruas, foram feitos os registros das informações. Entre estas, foram anotados dados das diferentes espécies como: nome vulgar, nome cientifico, diâmetro a 1,30 m do solo, altura total e altura livre dos ramos. Mediante consultas em literatura e profissionais da área de botânica, as espécies foram identificadas, permitindo sua classificação em famílias, gêneros, espécies (exóticas e nativas).

No trabalho, foram considerados todos os indivíduos lenhosos, exceto palmeiras, com DAP $\geq 5 \mathrm{~cm}$. Para cada indivíduo registou-se sua identidade taxonômica. Assim, a partir deste levantamento foram avaliados distintos parâmetros dendrométricos, entre eles:

Diâmetro (1,30 m): classificação individual que se define como o diâmetro ou grossura que o indivíduo alcança a 1,30 metros do nível do solo, também denominado diâmetro à altura do peito (DAP), medido com uma fita diamétrica.

Altura total $(\mathrm{m})$ : dado individual que se define como a elevação que cada indivíduo alcançou sobre a superfície do terreno, determinado pelo método ocular. 
Altura livre dos ramos $(\mathrm{m})$ : classificação individual de cada exemplar e define-se como a elevação alcançada pelo indivíduo em relação ao solo até onde inicia a folhagem, determinado pelo método ocular.

\section{Análise Estatística}

O processamento dos dados realizou-se mediante os pacotes estatísticos Stadistical Package for Social Science (SPSS) 15.0 para Windows e BioDiversity Prosessional 2.0, além de utilizar a Microsoft Excel na confecção de tabelas e figuras e Microsoft Office Word para a elaboração do documento.

\section{RESULTADOS E DISCUSSÃO}

\section{Validação da Amostragem}

A curva ruas-espécies (Figura 2) indica que a amostragem nas seis (6) ruas distribuídas na cidade do Huambo foi suficiente para representar a composição florística. De acordo à tendência da curva de espécies obtida não há um aumento significativo do número de espécies com o aumento do tamanho da amostra, já que, a curva mantem-se constante a partir da quinta amostragem, aspecto importante para a validação do tamanho da amostragem segundo Schilling, Ferreira e Do Couto (2012). Isto indica que a maioria das espécies foi identificada, no entanto, trabalhou-se com as seis ruas para maior representatividade.

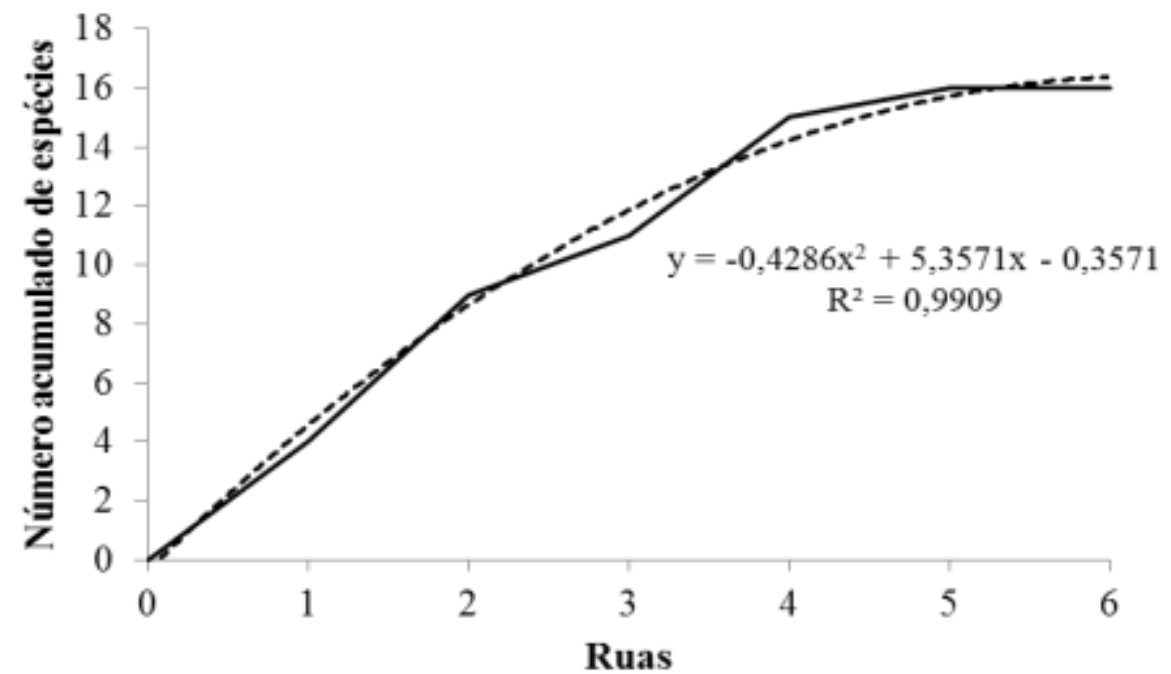

Legenda: 1. Rua Doutor Carlos Ferreira; 2. Rua Presidente Craveiro Lopes; 3. Av. Norton de Matos; 4 . Rua 5 de Outubro; 5. Rua Ferreira Viana; 6. Avenida da República.

Figura 2. Número acumulado de espécies por ruas obtidas a partir da amostragem na cidade do Huambo-Angola

Figure 2. Cumulative number of species for street obtained from sampling in Huambo city - Angola 
Além disso, uma vez que o valor da regressão linear $\left(R^{2}=0.9909\right)$ é aproximadamente um, isto indica que as seis ruas são suficientes para representarem o número acumulado de espécies.

\section{Espécies Encontradas nas Ruas}

\section{Riqueza de espécies}

O inventário realizado permitiu saber que a vegetação urbana nas ruas estudadas está composta por 11 famílias botânicas, 16 géneros, 16 espécies e 552 indivíduos. Tendo em conta as espécies de árvores identificadas, notou-se que $75 \%$ são exóticas e $25 \%$ nativas, e em função do hábito de crescimento existem espécies de crescimento médio e rápido em muitos dos casos (Tabela 1).

Tabela 1. Distribuição das espécies presentes nas ruas estudadas $(E=$ exótica para Angola, $N=$ nativa para Angola)

Table 1. Distribution of species present in the studied streets $(E=$ exotic to Angola, $N=$ native to Angola)

\begin{tabular}{|c|c|c|c|c|c|}
\hline Famílias & Nome científico & Nome local & Origem & $\mathbf{F a}$ & $\operatorname{Fr}(\%)$ \\
\hline Araucariaceae & $\begin{array}{c}\text { Auracaria columnaris (Forst.) } \\
\text { Hook. }\end{array}$ & Araucária-excelsa & $\mathrm{E}$ & 1 & 0,18 \\
\hline Euphorbiaceae & Aleurites molucana (L.) Willd. & Nogueira-de-iguape & $\mathrm{N}$ & 1 & 0,18 \\
\hline Lauraceae & Persea gratissima Gaertn & Abacateiro & $\mathrm{E}$ & 1 & 0,18 \\
\hline Fabaceae & Bauhinia vaiegata $L$. & Pata-de-vaca & $\mathrm{E}$ & 4 & 0,72 \\
\hline Malvaceae & $\begin{array}{l}\text { Brachychiton populneu (Schott } \\
\text { \& Endl.) R. Br. }\end{array}$ & $\begin{array}{l}\text { Perna-de-moça; } \\
\text { braquiquito }\end{array}$ & $\mathrm{N}$ & 90 & 16,30 \\
\hline Myrtaceae & $\begin{array}{l}\text { Callistemon viminalis (Sol. Ex } \\
\text { Gaertn.) G. Don ex Loud. }\end{array}$ & $\begin{array}{l}\text { Escova-de-garrafa- } \\
\text { pendente }\end{array}$ & $\mathrm{E}$ & 11 & 1,99 \\
\hline Fabaceae & Cassia fistula $\mathrm{L}$. & Cássia-imperial & $E$ & 65 & 11,78 \\
\hline Casuarinaceae & $\begin{array}{c}\text { Casuarina equisetifolia J. R. \& } \\
\text { G. Forst. }\end{array}$ & Casuarina & $\mathrm{E}$ & 128 & 23,19 \\
\hline Cupressaceae & Cupressus lusitânica Mill. & Cedro; Cipreste & $E$ & 5 & 0,91 \\
\hline Myrtaceae & $\begin{array}{c}\text { Eucalyptus grandis W. Hill ex } \\
\text { Maiden }\end{array}$ & Eucalipto & $\mathrm{E}$ & 1 & 0,18 \\
\hline Moraceae & Ficus auriculata Lour. & Figueira de jardim & $\mathrm{N}$ & 1 & 0,18 \\
\hline Fabaceae & Gleditsia triacanthos L. & Espinho-de-Cristo & $\mathrm{E}$ & 105 & 19,03 \\
\hline Malvaceae & Hibiscus rosa-sinensis L. & Hibisco & $E$ & 1 & 0,18 \\
\hline Bignoniaceae & Jacaranda mimosifolia D. Don & Jacarandá & E & $\begin{array}{c}10 \\
8\end{array}$ & 19,57 \\
\hline Fabaceae & $\begin{array}{l}\text { Leucaena leococephala } \\
\text { (Lam.) R. de Wit }\end{array}$ & Leucena & $\mathrm{E}$ & 3 & 0,54 \\
\hline Bignoniaceae & Spathodea nilótica Seem & $\begin{array}{c}\text { Bisnagueira; } \\
\text { Tulipeira-da-África }\end{array}$ & $\mathrm{N}$ & 27 & 4,89 \\
\hline SOMA & & & & 552 & 100 \\
\hline
\end{tabular}

Onde: $\mathrm{N}$ = nativa, $\mathrm{E}=$ exótica, $\mathrm{Fa}=$ frequência absoluta, $\mathrm{Fr}(\%)$ = frequência em percentagem. 
O inventário demostrou que as espécies de maior frequência relativa foram: Casuarina equisetifolia J. R. \& G. Forst. (23,19\%); Jacaranda mimosifolia D. Don (19,03\%); Brachychiton populneu (Schott \& Endl.) R. Br. (16,30\%) e Cassia fistula L. (11,78\%), todas acima dos $10 \%$. Essas quatro (4) espécies somam 70,29\% do total de indivíduos amostrados.

Dentro das espécies mais frequente destaca-se com a maior percentagem (23,19\%) a Casuarina equisetifolia, influenciado pelo maior número de indivíduos (128) o que indica sua boa adaptabilidade às condições edafoclimáticas do Huambo. Além disto esta espécie foi uma das primeiras espécies plantadas na cidade depois da independência como estratégia na arborização urbana.

Em relação à $C$. equisetifolia Tovar-Corzo (2013), expõe que a espécie está contraindicada nas atividades de urbanização por ter o sistema radicular superficial, o que pode ocasionar rachaduras nos passeios e queda de árvores, devido às grandes dimensões que alcançam em altura.

A segunda espécie mais frequente foi Jacaranda mimosifolia $(19,03 \%)$ que ao contrário da Casuarina, é recomendada para os trabalhos de arborização, podendo também ser utilizada para o paisagismo de parques e grandes jardins (LORENZI et al., 2003). A elevada frequência de Jacaranda mimosifolia é consequência dos plantios realizados na cidade de Huambo durante os últimos planos de gestão na arborização urbana.

A alta frequência (superior a 70\%) de espécies exóticas, demonstrada no presente estudo revela ausência de preocupação com a conservação da flora nativa. Resultados semelhantes foram obtidos no Brasil por Camilo et al. (2013), que afirmam que em praticamente todas as cidades brasileiras há uma predominância na utilização de espécies exóticas na arborização urbana, em detrimento das possibilidades de se explorar a riqueza da flora local.

Resultado diferente foi encontrado no trabalho de Assunção et al. (2014) em Cáceres - MT, correspondendo a 135 (58,44\%) dos indivíduos nativos e $96(41,56 \%)$ exóticos.

Segundo Silva et al. (2008), deve-se optar na arborização urbana por espécies nativas e espécies típicas da fitogeografia de cada cidade, devido as mesmas contribuírem para o equilíbrio biológico, recuperação e manutenção da fitofisionomia da paisagem. Além disso, a presença de espécies exóticas sobrepondo as nativas em um ambiente pode promover perda da biodiversidade, bem como uma adaptação dessas espécies que passam a ocupar os espaços das espécies nativas (BLUM, 2008; ABENDROTH et al., 2012).

$\mathrm{Na}$ Tabela 2 pode-se observar a distribuição da vegetação em valores percentuais por cada família, gênero e espécie coincidindo com o número total de gêneros e espécies (16) que as 11 famílias inventariadas possuem. A família Fabaceae é a que apresenta maior número de gêneros e espécies com 25,0 \% para ambos os casos, seguida da Myrtaceae e Bignonaceae 
com 12,50 \%. Estas percentagens citadas à cima, fundamentalmente, para a família Fabaceae são superiores no caso do género e espécie em relação ao recomendado por SANTAMOUR JÚNIOR (1990) onde considera que deve existir um equilíbrio entre ambas o qual não deve ultrapassar o 30\% de uma única família de árvores, $20 \%$ de um único género e 10\% de uma única espécie.

Isto deve-se a ausência de uma boa planificação e falta de uma adequada seleção e diversificação de espécies nos trabalhos de arborização das ruas desta cidade. No entanto, as restantes famílias têm apenas $6,25 \%$ de participação nas ruas estudadas, em função do gênero e da espécie.

O predomínio da família Fabaceae reafirma os resultados encontrados em outros trabalhos dessa natureza, que também verificaram a predominância desta família em relação à riqueza de árvores urbanas (KURIHARA; IMAÑA-ENCINAS; PAULA, 2005; PIRES et al., 2010; LAYOLA et al., 2013). Além disso, um fato muito evidente é que Fabaceae é a família mais comum encontrada em florestas tropicais e florestas secas nas Américas e na África.

Tabela 2. Famílias, gêneros e espécies com sua proporção relativamente às 16 espécies identificadas Table 2. Families, genera and species with their proportion compared to the 16 identified species

\begin{tabular}{clcccc}
\hline $\mathbf{N}^{\mathbf{0}}$ & Famílias & Gêneros & \% nas ruas & Espécies & \% nas ruas \\
\hline 1 & Araucariacea & 1 & 6,25 & 1 & 6,25 \\
2 & Euphorbiaceae & 1 & 6,25 & 1 & 6,25 \\
3 & Lauraceae & 1 & 6,25 & 1 & 6,25 \\
4 & Fabaceae & 4 & 25,0 & 4 & 25,0 \\
5 & Sterculiaceae & 1 & 6,25 & 1 & 6,25 \\
6 & Myrtaceae & 2 & 12,5 & 2 & 12,5 \\
7 & Casuarinaceae & 1 & 6,25 & 1 & 6,25 \\
8 & Pinaceae & 1 & 6,25 & 1 & 6,25 \\
9 & Moraceae & 1 & 6,25 & 1 & 6,25 \\
10 & Malvaceae & 1 & 6,25 & 1 & 6,25 \\
11 & Bignonaceae & 2 & 12,5 & 2 & 12,5 \\
\hline \multicolumn{7}{c}{ Total } & $\mathbf{1 6}$ & $\mathbf{1 0 0}$ & $\mathbf{1 6}$ & $\mathbf{1 0 0}$ \\
\hline
\end{tabular}

É muito importante considerar a relação família-gênero-espécie para caracterizar as árvores no meio urbano, já que esta junção diminui os riscos de perda vegetativa por ataque intenso de pragas ou doenças (RABER; REBELATO, 2010).

Em relação aos diferentes parâmetros florísticos avaliados nas diferentes ruas amostradas (Tabela 3) verificou-se importante variação na distribuição dos indivíduos em cada rua, indicando a falta de critérios no planejamento da arborização, pois na Rua 5 de Outubro e a Avenida da Republica foram encontradas a maior parte das árvores, 53\% do total. 
Outros trabalhos também demonstraram a desarmonia na distribuição de espécies e indivíduos, indicando falta de planejamento da arborização urbana. Em um estudo realizado na cidade de Rio Grande, Brasil, foi encontrado a maior quantidade de indivíduos (44\%) em uma só via pública das quatro estudadas (DAMO et al., 2015) demostrando falta de critérios no planejamento da arborização.

Tabela 3. Parâmetros florísticos das ruas amostrados na cidade de Huambo-Angola Table 3. Floristic parameters of the sample streets in the city of Huambo-Angola

\begin{tabular}{ccccc}
\hline Ruas & Indivíduos & Famílias & Gêneros & Espécies \\
\hline 5 de Outubro & 192 & 14 & 14 & 14 \\
Norton de Matos & 71 & 5 & 5 & 5 \\
Presidente Craveiro Lopes & 54 & 5 & 5 & 5 \\
Doutor Carlos Ferreira & 83 & 3 & 4 & 4 \\
Avenida da República & 100 & 6 & 6 & 6 \\
Ferreira Viana & 52 & 6 & 6 & 6 \\
\hline
\end{tabular}

Os aspectos acima expostos, concernente a frequência simultânea de certas espécies nas Ruas 5 de Outubro e Presidente Craveiro Lopes, assim como na Avenida da República mostram semelhança quanto à composição florística entre elas, o que é claramente evidenciado no dendrograma resultante da análise de classificação das ruas como unidade de amostragem (Figura 3).

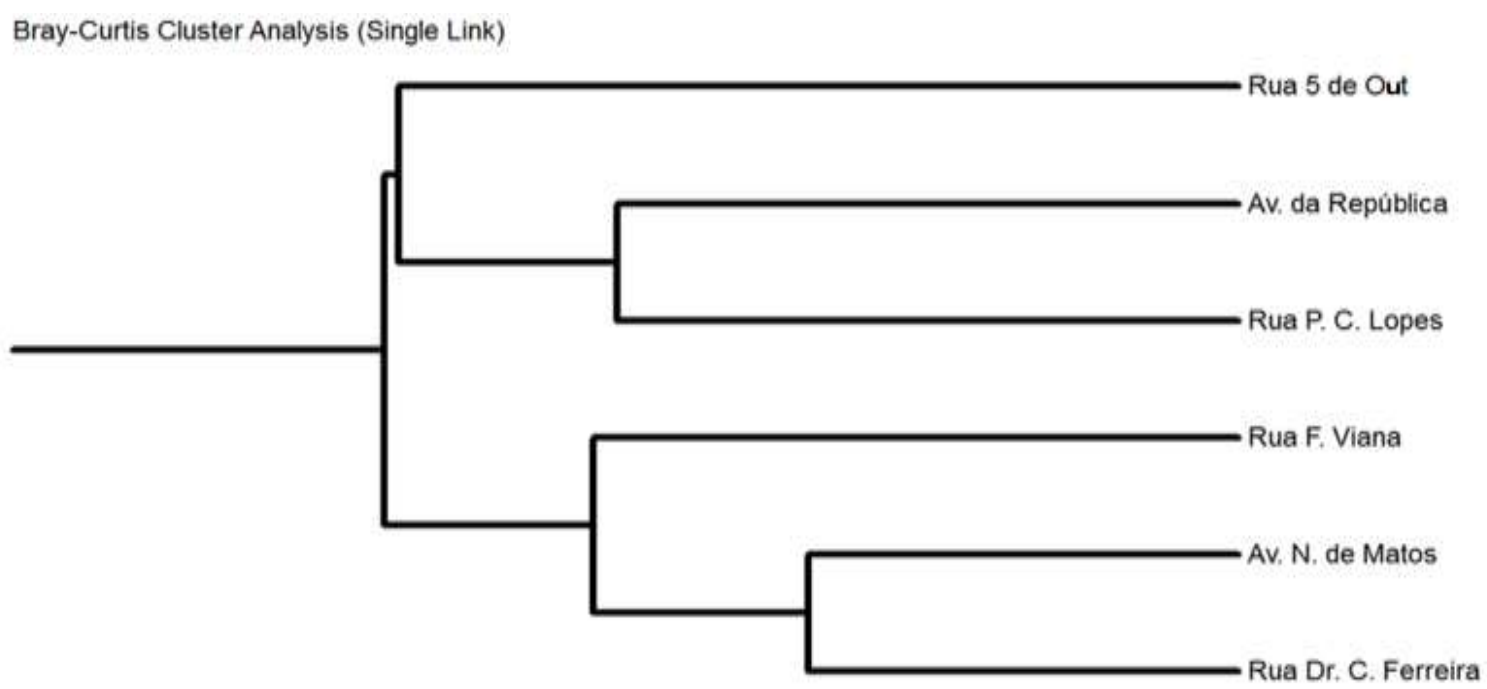

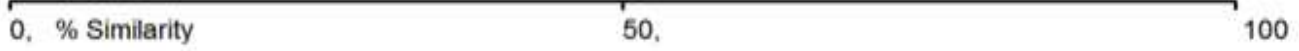

Figura 3. Dendrograma florístico obtido pela análise de conglomerado mediante a semelhança de BrayCurtis para as ruas da cidade do Huambo-Angola

Figure 3. Floristic dendrogram obtained by cluster analysis by the similarity of Bray-Curtis for the streets of Huambo city - Angola 
A análise de conglomerado permitiu distinguir duas agrupações com três ruas em cada grupo. O grupo I está formado por três ruas (Doutor Carlos Ferreira, Avenida Norton de Matos e Rua Ferreira Viana) com mais de 65\% de semelhança. O segundo grupo está representado por outras três vias (Rua Presidente Craveiro Lopes, Avenida da República e Rua 5 de Outubro) com mais de $50 \%$ de semelhança. Esta semelhança quanto à composição florística pode estar relacionada ao manejo e planejamento das espécies em cada sítio que propicie a variabilidade paisagística. No entanto, não só permite conhecer este fato como também ajuda na tomada de decisões mais precisas, além de fornecer indicativos importantes para maximizar as potencialidades e minimizar os problemas quanto à arborização urbana.

\section{Características Dendrométricas}

\section{Diâmetro do tronco}

A Rua Ferreira Viana apesar de apresentar um dos menores valores médios de altura total $(11,11 \mathrm{~m})$ é a que apresenta o maior valor médio em diâmetro $(36,87 \mathrm{~cm})$, valor que pode estar influenciado pelas constantes atividades de podas mal dirigidas nesta e outras ruas, como é o caso da Rua Doutor Carlos Ferreira. O mesmo não acontece com a Avenida da República que apresenta-se na segunda posição tanto em valores médios de altura total (11,78 m) e quanto os valores médios de diâmetro $(33,17 \mathrm{~cm})$, fato que está associado à sua localização numa zona da cidade em que a vegetação está submetida frequentes tratamentos silvícolas.

\section{Altura total}

A Avenida Norton de Matos apresenta o maior valor médio em altura total (13,04 m). Isto deve-se ao fato desta rua estar localizada entre dois pontos muito importantes e, portanto, visitados da cidade (Largo Doutor António Agostinho Neto e o Jardim da Cultura) recebendo assim melhor atenção e cuidado por parte dos gestores da vegetação urbana do Huambo. Aliás quem conhece esta cidade vê constantemente a presença de técnicos da Administração Municipal cuidando da vegetação presente naquela zona da cidade, ou seja, quase todos os trabalhos de tratamentos e cuidados da vegetação urbana feitos na cidade estão mais concentrados nesta importante zona da cidade, facto que também pode ser observado na Avenida da República que intercepta com o Largo Doutor António Agostinho Neto e apresenta segundo maior valor médio em altura total $(11,78 \mathrm{~m})$.

A Rua 5 de Outubro apresenta tanto menor valor médio em altura total $(10,12 \mathrm{~m})$ quanto segundo menor valor médio em diâmetro $(27,76 \mathrm{~cm})$, tudo isto está associado à 
presença do elevado número de vegetação jovem nesta área em relação as demais, pois que esta rua por ser a porta de entrada da cidade do Huambo desde o tempo colonial tem sido prioridade nos últimos planos de arborização urbana da Administração Municipal (Tabela 3).

\section{Altura livre dos ramos}

Os valores de altura livre dos ramos são muitos relativos em função das constantes podas parciais e totais a que as árvores estão submetidas o que muitas vezes ocasiona morte das plantas, bem como deformações no fuste, afetando o ambiente urbano quanto a sua beleza. Assim, os valores da altura livre tendem a ser, geralmente, abaixo para a maioria das plantas e, portanto, influenciando negativamente no momento de obter conclusões de um todo.

Tabela 3. Parâmetros dendrométricos das espécies mais representativas

Table 3. Dendrometric parameters of the more representative species

\begin{tabular}{cccc}
\hline Ruas & $\mathbf{d}(\mathbf{c m})$ & $\mathbf{h}(\mathbf{m})$ & $\mathbf{h r}(\mathbf{m})$ \\
\hline Rua 5 de Outubro & 27,76 & 10,12 & 3,67 \\
Avenida Norton de Matos & 28,24 & 13,04 & 3,81 \\
Rua Presidente Craveiro Lopes & 25,88 & 11,13 & 3,97 \\
Rua Doutor Carlos Ferreira & 31,85 & 11,62 & 3,87 \\
Avenida da República & 33,17 & 11,78 & 3,76 \\
Rua Ferreira Viana & 36,87 & 11,11 & 3,68 \\
Média & $\mathbf{3 0 , 6 3}$ & $\mathbf{1 1 , 4 7}$ & $\mathbf{3 , 7 9}$ \\
\hline
\end{tabular}

Onde: $\mathrm{d}=$ diâmetro a $1,30 \mathrm{~m} ; \mathrm{h}=$ altura total; $\mathrm{hr}=$ altura livre dos ramos.

A avaliação dos parâmetros dendrométricos antes expostos é de grande importância, já que permite conhecer as características morfológicas atuais das árvores que ajudam a ponderação qualitativa como a compatibilidade entre seu porte e o espaço, necessidade de poda, tratamento ou remoção, aspectos necessários para tomada de decisões, além da identificação da necessidade de intervenções.

Algumas bibliografias recomendam a avaliação dos parâmetros dendrométricos nos trabalhos de arborização, visto que possibilitam a identificação de proposta de manejo variado e a dinâmica das árvores, assim como dados relativos à sua nomenclatura, condições do sistema radicular, estabilidade da árvore, entre outros, os quais devem ser atualizados periodicamente (JIMÉNEZ, 2009; VICENTE; RONDON NETO, 2011).

Portanto, é de suma importância conhecer a vegetação da região, dentro da cidade e nos arredores, procurando selecionar espécies que são recomendadas para a arborização urbana de acordo com seu porte e adequação dos locais, e que apresentam crescimento e vigor satisfatórios. 
É comum a observação da excessiva prática de podas nesta cidade. Vê-se a grande preocupação com a estética da vegetação arbórea da cidade, porém isto é feito sem o cuidado pelo estado fisiológico das árvores. Pelo que nota-se claramente que não há uma boa relação entre os valores elevados de diâmetro e os reduzidos de altura.

Ao fazer a análise de correlação de Pearson entre a variável altura total e diâmetro a altura do peito (DAP) na Tabela 4, vê-se um coeficiente de $(r=-0,066)$, sendo a correlação negativa no nível de 0,01 . Portanto, o coeficiente não é significativo ( $99 \%$ de confiança que a correlação seja verdadeira e $1 \%$ de probabilidade de erro).

Tabela 4. Correlação de Pearson para a altura total e diâmetro.

Table 4. Pearson's correlation to the total height and diameter.

\begin{tabular}{cccc}
\hline & Variáveis & Altura & Diâmetro \\
\hline \multirow{2}{*}{ Altura } & Correlação de Pearson & 1 &,- 066 \\
& Sig. (bilateral) & &, 118 \\
& $\mathrm{~N}$ & 552 & 552 \\
\hline \multirow{2}{*}{ Diâmetro } & Correlação de Pearson &,- 066 & 1 \\
& Sig. (bilateral) &, 118 & \\
& $\mathrm{~N}$ & 552 & 552 \\
\hline \multicolumn{2}{c}{ Nota: A correlação é significativa ao nível 0,01 (bilateral). }
\end{tabular}

De modo geral não existe uma relação linear entre estas variáveis, isto quer dizer que os baixos valores da altura estão geralmente associados aos altos valores do DAP. Ou seja, os indivíduos cujos diâmetros são maiores não correspondem com os de maior altura. O lógico é que os indivíduos com maiores alturas correspondam aos de maiores diâmetros, visto que são duas variáveis lineares diretamente proporcionais. Este comportamento deve-se ao facto de que as árvores na cidade são podadas periodicamente para controlar seu crescimento, o que provoca um aumento no diâmetro do troco. Além disso, deve-se salientar que a falta de um organismo que cuida com técnicas ou princípios adequados das árvores da cidade e a falta de planejamento de projetos paisagísticos bem desenhado e de manejo da vegetação arbórea justificam a ausência de relação linear entre a altura e o diâmetro.

\section{CONCLUSÕES}

Feito o estudo chegou-se as seguintes conclusões:

a) As seis (6) principais ruas analisadas na cidade de Huambo - Angola apresentaram valores baixos de diversidade de espécies (16), das quais $75 \%$ são exóticas e apenas $25 \%$ são nativas; 
b) As vias públicas com maior número de indivíduos foram a Rua 5 de Outubro e Avenida da República com o 44\%, demostrando falta de planejamento da arborização urbana;

c) A avaliação da estrutura dendrométrica demonstra que as árvores, na sua maioria, são adultas, tendo médias de: altura total (11,47 m); altura livre dos ramos (3,79 m) e diâmetro $(30,63 \mathrm{~cm})$, além de algumas vezes necessitarem de reposições devido às péssimas condições morfológicas que as mesmas árvores apresentam.

\section{AGRADECIMENTOS}

À DEUS, o Eterno, a quem com o nosso modo de viver tributamos toda a honra, mérito e gratidão primaziamos nossos agradecimentos.

Nossa sincera e profunda gratidão estende-se:

À Professora Virgínia Lacerda Quartin (PhD), Vice-Reitora para Área Científica e Pósgraduação da Universidade José Eduardo dos Santos/Huambo - Angola, por todo seu apoio.

Ao Jornal Nova Gazeta que no PENG 2014 concedeu uma bolsa de estudo, que foi o principal suporte financeiro para a realização deste emblemático trabalho.

À Administração Municipal do Huambo por conceder alguns de seus dados.

Aos nossos familiares, amigos, colegas e todos que de uma ou outra maneira nos apoiaram e ainda apoiam para que nossa fidúcia cientifica seja perpétua.

\section{REFERÊNCIAS}

ABENDROTH, A.; KOWARIK. I.; MULLER. N.; LIPPE. M. The green colonial heritage: woody plants in park of Bandung, Indonesia. Landscape and Urban Planning, Amsterdam, v.106, n.1, p.12-22, 2012.

AGÊNCIA PRESS ANGOLA (ANGOP). Ministra do Ambiente constata execução de projectos no Huambo. p. 1. Disponível em: <http://www.portalangop.co.ao/angola/pt_pt/ noticias/ambiente/2013/4/22/Ministra-Ambiente-constata-execucao-projectos,f1e3871d-656942ca-ad2e-3f4890b38356.html>. Acesso em: 10 out. 2013.

ASSUNÇÃO, K. C.; LUZ, P. B.; NEVES, L. G.; PAIVA-SOBRINHO, S. Levantamento quantitativo da arborização de praças da cidade de Cáceres/MT. Revista da Sociedade Brasileira de Arborização Urbana, Piracicaba, v. 9, n. 1, p.123-132, 2014.

BLUM, C.T. Espécies exóticas invasoras na arborização de vias públicas de Maringá-PR. Revista da Sociedade Brasileira de Arborização Urbana, Piracicaba, v. 3, n. 2, p.78- 97, 2008. 
CAMILO, G. A. P. V.; BREGAGNOLI, M.; SOUZA, C. A. S. Levantamento da biodiversidade florística da arborização urbana em Guaxupé - Minas Gerais. Revista Agrogeoambiental, Pouso Alegre, v. 5, n. 1, p. 61-74, 2013.

DAMO, A.; HEFLER, S. M.; SOARES, U. Diagnóstico da arborização em vias públicas dos bairros Cidade Nova e Centro na Cidade de Rio Grande - RS. Revista da Sociedade Brasileira de Arborização Urbana, Piracicaba, v.10, n.1, p. 43-60, 2015.

DELGADO, C.; JIMÉNEZ, E; KIALA, D. Los Eucaliptos en las tierras altas de Angola, su papel social durante el conflicto armado y en el desarrollo de las comunidades rurales y urbanas. Boletín del Centro de Investigación y Documentación del Eucalipto, España, v. 1, n. 3, p. 99-107, 2007.

GOOGLE EARTH. Mapa da Cidade do Huambo. Angola, Huambo. 2015.

HAMADA, S.; OHTA, T. Seasonal variations in the cooling effect of urban green areas on surrounding urban areas. Urban Forestry \& Urban Greening, Davis, v.9, p. 15-24, 2010.

JIMÉNEZ, M. Desarrollo de la silvicultura urbana en Cuba: Perspectivas. Revista Agricultura Orgánica, Cuba, v.3, n. 5, p. 22-23, 2009.

KURIHARA, D. L.; IMAÑA-ENCINAS, J.; PAULA, J. E. Levantamento da arborização do Campus da Universidade de Brasília. Cerne, Lavras, v. 11, n. 2, p. 127-136, 2005.

LAYOLA, R.; FERREIRA, C. V.; RODRIGUEZ, J. P.; CLARO, A. G. Levantamento qualiquantitativo da arborização urbana do bairro Ferraropólis na cidade de Garça-SP. Revista da Sociedade Brasileira de Arborização Urbana, Piracicaba, v. 8, n. 1, p. 65-75, 2013.

LORENZI, H.; SOUZA, H M; TORRES, M A V; BACHER, L B, Árvores Exóticas no Brasil: madeireiras, ornamentais e aromáticas. Nova Odessa: Instituto Plantarum, 2003. 256 p.

MENDELSOHN, J.; WEBER, B. Atlas e perfil do Huambo: sua terra e suas gentes. 1. ed. Development Workshop: Luanda, Angola. 2013. 82 p.

PIRES, N.A.M.T.; MELO, M. S.; OLIVEIRA, D. E.; XAVIER-SANTOS, S. A arborização urbana do município de Goiandira/GO - Caracterização quali-quantitativa e propostas de manejo. Revista da Sociedade Brasileira de Arborização Urbana, Piracicaba, v. 5, n. 3, p.185-205, 2010.

RABER, A. P.; REBELATO, G. S. Arborização viária do município de Colorado, RS-Brasil: análise quali-quantitativa. Revista da Sociedade Brasileira de Arborização Urbana, Piracicaba, v.5, n.1, p.183-199, 2010.

SANTAMOUR JÚNIOR, F.S. Trees for urban planting: diversity uniformity, and common sense. In: Metria Conference, 7. 1990, Proceedings. Lisle: p.57-66, 1990.

SANTOS, T. O. B.; LISBOA, C. M. C. A.; CARVALHO, F. G. Análise da arborização viária do bairro de Petrópolis, Natal, RN: uma abordagem para diagnóstico e planejamento da flora urbana. Revista Brasileira de Arborização Urbana, Piracicaba, v. 7, n. 4, p. 90 - 106, 2012.

SCHILLING, A. C.; BATISTA, J. L. F. Curva de acumulação de espécies e suficiência amostral em florestas tropicais. Revista Brasileira de Botânica, São Paulo, v. 31, n. 1, p. 179-187, 2008. 
SCHILLING, A. C.; FERREIRA, J. L.; DO COUTO, H. Z. Ausência de estabilização da curva de acumulação de espécies em florestas tropicais. Ciência Florestal, Santa Maria, v. 22, n. 1, p. 101-111, 2012.

SILVA, L.M.; RODIGHIER, D.A.; HASSE I.; CADORIN D.A. Arborização dos Bairros Pinheiros, Brasília e Bancários em Pato Branco/PR. Scientia Agraria, Curitiba, v.9, n.3, p.275-282, 2008.

TOVAR-CORZO, G. Aproximación a la silvicultura urbana en Colombia. Revista Bitácora Urbano Territorial, Colombia, v.1, n. 22, p. 119-136, 2013.

VICENTE, U. G.; RONDON NETO, M. R. Arborização Urbana da Cidade de Reserva do Cabaçal - MT. Revista de Ciências Agro-Ambientais, Alta Floresta, v.9, n.1, p.31- 38, 2011.

VOLPE-FILIK, A.; SILVA, L. F. da; LIMA, A. M. L. P. Avaliação da Arborização de Ruas do Bairro São Dimas na Cidade de Piracicaba/SP através de Parâmetros Qualitativos. Revista da Sociedade Brasileira de Arborização Urbana, Piracicaba, v. 2, n. 1. p. 34-43, 2007.

WANDA, D. Roteiro da cidade do Huambo. Repartição de Ordenamento do Território, Urbanismo e Ambiente. Administração Municipal do Huambo, Angola. 2007. 1p. 